\title{
As Novas Diretrizes para a Transferência da Administração \\ Federal para Brasília
}

HÉLIO LOOBO

Presidente do GEMUD

\section{Considerações Preliminares}

Inaugurada a nova Capital da República em 21 de abril de 1960, a transferência dos órgãos da Administração Federal não teve uma seqüência normal. Nem qualitativa, nem quantitativa.

Ora vinham para Brasilia setores com alto número de funcionários, mas sem nenhuma significação para a dinâmica da Capital que surgia, ora setores de relêvo na Administração, mas vindo apenas simbòlicamente, permanecendo as bases na ve'ha sede, sem nenhuma alteração.

Tudo dependia, quase sempre, da vontade exclusiva do dirigente de cada órgão, mesmo porque as próprias verbas para a mudança ficavam vinculadas às numerosas unidades orçamentárias, sem coordenação superior.

Se o dirigente via Brasília com bons Olhos, a aplicação se fazia normalmente. Se desgostava da cidade, os recursos eram logo oferecidos como compensação, na primeira oportunidade, e aplicados em outras áreas.

Outro ponto de estrangulamento da mudança era o problema residencial. o Govêrno construía sempre, mas os apartamentos eram vendidos aos respectivos ocupantes, sem nenhuma restrição.

Quando alguma autoridade pretendia transferir-se para a Capital não tinha onde morar. A solução era a hospedagem em hotéis, às expensas do Poder Público.

\section{A CONSTITUIÇÃO DE 1967 E A MUDANÇA}

Com o advento da Consti uição de 24 de janeiro de 1967, as coisas passaram a tomar nôvo rumo.

De fato, seu artigo 183 estabe'ecia expressamente:

"Dentro de cento e oitenta dias, a partir da vigência desta Constituição, o Poder Executivo envia- 
rá ao Congresso Nacional projeto de lei regulando a mudança, para a Capital da União, dos órgãos federais que ainda permaneçam no Estado da Guanabara".

\section{A LEI NO $5.363 / 67$ E O} DECRETO-LEI № 200/67

Cumprindo o dispositivo constitucional, a Lei n? 5.363, de 30 de novembro de 1967, fixou normas disciplinadoras para a mudança, interligando-a com a Reforma Administrativa.

Foi um passo decisivo.

De um ladö, não se poderia promover a transferência para Brasília da totalidade da grande massa de servidores da União existentes no Estado da Guanabara.

Por outro lado, a nova filosofia administrativa que se implantava no País era a da descentralização.

Com isto, muitos órgãos não deveriam mais sediar-se na Capital da República, pois as suas atribuições seriam descentra'izadas.

O Decreto-lei n? 200 , de 25 de fevereiro de 1967, ao fixar diretrizes para a descentralização das atividades da Administração Federal, estabeleceu, entre outros pontos, os seguintes:

a) distinção clara, dentro dos quadros da Administração, entre os níveis de direção e os de execução;

b) estrutura de tal ordem que os serviços de direção permaneçam liberados das rotinas de execução e das tarefas de mera formalização de atos administrativos, para que possam concentrar-se nas atividades de planejamento, supervisão, coordenação e contrôle; c) a administração casuística, assim entendida a decisão de casos individuais, compete, em princípio, ao nivel de execução.

Como fruto dessa nova política na administração, a Lei $n$ ? 5.363 , de 30 de novembro de 1967 , entre outras normas, determinou:

"Art. 1o A transferência de órgãos e servidores da Administração Federal para Brasília far-se-á com observância das diretrizes da Reforma Administrativa e especialmente do principio de descentralização executiva.

Art. 20. Deverá localizar-se na Capital da União o núcleo central da Administração Federal, assim entendidos os órgãos e servidores incumbidos:

1 - do assessoramento direto ao Presidente da República;

II - do planejamento e coordenação geral das atividades da Administração Federal;

III - do assessoramento direto aos Ministros de Estado e do planejamento, coordenação e contrôle superior das atividades a cargo de cada Ministério.

Art. 3 ? Em decorrência do art. 2. localizar-se-ão necessàriamente em Brasília:

1 - os Ministros de Estado;

II - os Gabinetes Civil e Militar da Presidência da República;

III - a Secretaria do Conse'ho de Segurança Nacional;

IV - a Chefia e. a Agência Central do Serviço Nacional de Informações; 
V - o Estado-Maior das Fôrças Armadas;

VI - a Diretoria-Geral do DASP

- Departamento Adminisrtativo do Pessoal Civil;

VII - a Consultoria-Geral da República;

VIII - o Núcleo Central de cada Ministério incumbido das funções referidas no inciso III do art. 2 . $\S 1$ ? A definição dos órgãos e servidores abrangidos pelo inciso VIII dêste artigo será feita em cada caso por ato do Presidente da República, uma vez realizados os trabalhos de revisão, descentralização, simplificação e reestruturação de que trata 0 título XIII do Decreto-lei no 200, de 25 de fevereiro de 1967.

$\S 2$ ํ. Localizar-se-ão ainda em Brasilia as unidades e organizações das Fôrças Armadas que forem definidas por ato do Presidente da República, tendo em vista as conveniências de segurança nacional".

\section{DEFINIÇÃO DE NÚCLEO CENTRAL}

Tão logo foi expedida essa Lei, preocupou-se o Ministério do Planejamento e Coordenação Geral, como responsável pela sua execução e pela supervisão geral da mudança, com a definição do núcleo central de cada Ministério.

Ocorre que dificuldades foram encontradas, nesse trabalho, em face da estrutura diversa dos Ministérios.

Alguns já haviam instalado em Brasília órgãos centrais de direção superior, mas não exclusivamente de planejamento e assessoramento imediato.
Outros dispunham de departamentos específicos, indicando a necessidade de apreciação mais demorada.

O estabelecimento, de imediato, de uma definição ao mesmo tempo genérica e abrangente de tôdas as peculiaridades de cada organismo demandaria algum tempo e tornaria extremamente moroso o processo de mudança.

Após estudos em conjunto com as diversas Secretarias de Estado, ficou convencionado que deveriam transferir-se para Brasilia, desde logo, os seguintes órgãos, comuns a todos os Ministérios, sem prejuizo de complementação posterior quanto aos demais:

Gabinete do Ministro

Secretaria-Geral

Divisão de Segurança e Informações

Consultoria Jurídica

Inspetoria-Geral de Finanças

Departamento de Administração.

\section{CRIAÇÃO DO GEMUD}

Posteriormente, pelo Decreto-lei $n$ ? 391 , de 30 de dezembro de 1968, regulamentado pelo Decreto $n^{\circ} 63.920$, da mesma data, foi criado um colegiado especial, o GEMUD, constituído de representantes da Presidência da República, do Ministério do Planejamento e Coordenação Geral, do Govêrno do Distrito Federal e da CODEBRAS, para coordenar a mudança, sob a supervisão do Ministro do Planejamento e Coordenação Geral, com atuação nas seguintes áreas:

a) execução da política de transferência da Administração Federal para Brasília, com fixaçăo de prioridades;

b) acompanhamento da elaboração e da execução dos cronogramas de 
mudança da Administração Direta $\Theta$ Indireta;

c) destinação de sedes para a Administração Direta, abrangendo construções e reconstruções;

d) destinação de residências funcionais aos ocupantes de cargos em comissão e funçōes gratificadas pertencentes aos núcleos centrais dos Ministérios;

e) entrosamento com o Govêrno do Distrito Federal, na execução das atividades mencionadas, inclusive cooperação na indicação de obras prioritárias de infra-estrutura de interêsse para a mudança.

Dentro da nova linha traçada para a mudança, o Decreto $n$ ํ 63.920/68, já mencionado, estabeleceu que não deveriam integrar os núcleos centrais, em transferência para Brasilia, escriturários, datilógrafos, motoristas, continuos, serventes e outras funções auxiliares, cujo recrutamento seria feito no Distrito Federal.

Outra providência veio em seguida: os recursos orçamentários para a mudança, inclusive construção e reconstrução de sedes e residências, ficaram centralizados no Ministério do Planejamento e Coordenação Geral, para melhor coordenação e execução dos programas prioritários fixados pelo Govêrno.

NOVA ESTRUTURA PARA A CODEBRAS

A CODEBRÅS, criada pelo Decretolei $n$ ? 302, de 28 de fevereiro de 1967 , substituiu o antigo G.T.B., na execução da política de transferência.

Foi reestruturada pelo Decreto $n$ ? 65.719 , de 20 de novembro de 1969 , que the deu mais flexibilidade de ação, para atuar de acôrdo com as novas diretrizes governamentais para a consolidação da Capital.

Entre suas atribuições, como órgão vital na execução da mudança, cabe à CODEBRAS a gestăo do Fundo Rotativo Habitacional de Brasília, destinado a financiar residências aos servidores federais.

Atravessando uma fase de grande expansão, totalmente mobilizada para a mudança, é a CODEBRÁS a detentora do maior volume de obras residenciais ora em execução na Capital Federal, dentro do esquema de transferência.

\section{APARTAMENTOS FUNCIONAIS}

A nova legislação criou também a figura dos apartamentos funcionais, construídos com verbas orçamentárias e destinados aos titulares de cargos em comissão ou funções gratificadas, em exercicio nos núcleos centrais dos Ministérios.

Tais apartamentos não são vendidos, nem sujeitos à legislação do inquilinato, mas utilizados em função do cargo do ocupante, que paga apenas uma taxa de ocupação e o condomínio, obrigando-se a restituir o imóvel, caso seja substituido, dentro de 60 dias.

Com isto, haverá sempre residências para o pessoal de nível mais elevado nos Ministérios.

O EMFA e os Ministérios Militares, mediante esquemas próprios, vêm desenvolvendo uma obra extraordinária de fixação em Brasília, abrangendo sedes, hospitais, serviços diversos e residências. 
As representações diplomáticas estrangeiras dia a dia vão chegando.

As grandes emprêsas começam a trazer seus escritórios.

As entidades da Administração Indireta, a exemplo da Administração Direta, também se movimentam com a mudança.

Ainda recentemente, dirimindo omissões e dúvidas, fol baixado o Decreto n tabelecendo que, salvo disposição expressa de lei ou decreto, o Distrito Federal é a sede das entidades autárquicas, emprêsas públicas e sociedades de economia mista da Unlão.

O Banco Central e o Banco do Brasil já instalaram suas Diretorias na Capital, em plena execução de um rigido programa de mudança.

Alguns outros dados elucidarão meIhor a tarefa já realizada, sob a coordenação direta do Ministro Reis Veloso, do Planejamneto e Coordenação Geral.

Como o número de Ministérios foi ampliado, pelo Decreto-iei n? 200/67, estão em construção na Península dos Ministros casas para os novos titulares.

A conclusão dessas novas residênclas está prevista para dezembro dêste ano.

\section{RESULTADOS JÅ ALCANÇADOS}

Os resultados da nova orientação para a mudança, com a diretriz inflexível do Presidente Médici no sentido de consolidar a Capital, são dos mais expressivos.
Os núcleos centrais da maioria dos Ministérios já funcionam em Brasilia. 0 que ainda falta terá condiçóes tranqüilas para instalar-se nos próximos meses, graças ao considerável volume de residências funcionais ora em construção pela CODEBRAS.

As grandes decisões dos alios problemas nacionais são tomadas na $\mathrm{Ca}$ pital Federal.

Os congressos e reuniöes de nivel mais elevado na Administraçăo se repetem em Brasília.

O Poder Judiciário e o Congresso Nacional aí estão.

\section{PROGRAMA DE SEDES}

Como fruto dêsse trabalho, foram concluídos ou reconstruidos os edifisios dos seguintes Ministérios: Relações Exteriores, Agricultura, Fazenda, Indústria e do Comércio.

Em construção adiantada encontram-se as novas sedes dos Ministérios da Justiça e das Minas e Energia, devendo ser iniciada agora a construção dos edifícios dos Minisiérios das Comunicações e do Planejamento e Coordenação Geral, bem como da Procuradoria-Geral da República.

$\mathrm{Na}$ área do Poder Judiciário, concluíram-se os edificios do Tribunal Federal de Recursos, do Superior Tribunal Eleitoral e do Tribunal Superior do Trabalho, encontrando-se em construção o anexo do Supremo Tribunal Federal e a sede do Superior Tribunal Militar, que deverá transferir-se no próximo ano. 
PROGRAMAÇÃO DE 1970

Os recursos com programas de sedes, infra-estrutura e residências, em 1970, foram os seguintes, entre outros alocados em programas especiais:

\section{Sedes}

Ministério das Relações Exteriores .................. $6.351 .109,00$

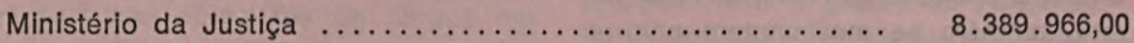

Ministério da Indústria e do Comércio ............... $1.000 .000,00$

Ministério da Fazenda . ........................ $\quad 731.000,00$

Ministério das Comunicações .................... $2.500 .000,00$

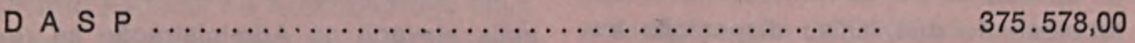

Departamento de Polícia Federal .................. $\quad 1.279 .431,00$

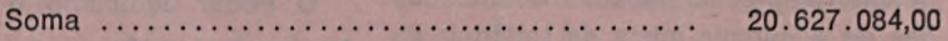

OBRAS DE INFRA-ESTRUTURA

Para obras de infra-estrutura de interêsse direto para a mudança foram destinados os seguintes recursos:

N O V A C A P ................................ $\quad 8.150 .000,00$

Companhia de Água e Esgotos . ................... 1.143.275,53

Universidade de Brasília ......................... $\quad 1.200 .000,00$

Companhia de Eletricidade de Brasília ................. 230.004,47

C O TELB ............................... $324.044,05$

Soma $\ldots \ldots \ldots \ldots \ldots \ldots \ldots \ldots \ldots \ldots \ldots \ldots \ldots \ldots \ldots \ldots \ldots \ldots+11.047 .324,05$

PROGRAMAS DE RESIDENCIAS FUNCIONAIS

C O DEBRÁS

$65.502 .300,00$

RESUMO DE 1970

Sedes

$20.627 .084,00$

Infra-estrutura

$11.047 .324,00$

Residências

$65.502 .300,00$

Total

$97.176 .708,00$ 
PROGRAMAÇÃO PARA 1971

Em 1971, a programação já aprovada e em execução, até o momento, é a seguinte:

\section{Sedes}

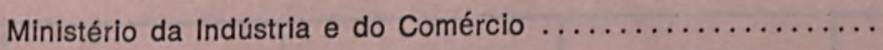

2. $440.000,00$

Ministério da Justiça

$4.000 .000,00$

Ministério das Relações Exteriores

$1.500 .000,00$

Ministério da Fazenda

$2.500 .000,00$

Ministério do Trabalho e Previdência Social

$1.035 .000,00$

Ministério da Saúde

$875.000,00$

Ministério Público Federal

2.150.000,00

Departamento de Polícia Federal

$3.000 .000,00$

Soma

$17.500 .000,00$

RESIDENCIAS FUNCIONAIS

CODEBRAS

$72.500 .000,00$

SERVIÇOS ESPECIAIS

Programa de Mudança - CODEBRAS

$7.500 .000,00$

RESUMO DE 1971

Sedes

$17.500 .000,00$

Residências funcionais .

$72.500 .000,00$

Programa de mudança

$7.500 .000,00$

Soma

$97.500 .000,00$

O PROBLEMA DE RESIDENCIAS

Os programas citados referem-se à construção de residências funcionais, já definidas anteriormente.

Quanto ao financiamento para a casa própria do servidor público, os Ministérios e outros órgãos geralmente têm feito convênios com a Caixa Econômica Federal, para atendimento de seus funcionários.

A CODEBRAS, gestora do Fundo Rotativo Habitacional de Brasília, ini- ciou a execução de um plano para atender aos servidores federais ainda carentes de habitação.

Pela Portaria Interministerial $n$ : 34 , de 16 de abril de 1971 , os Ministros do Planejamento e Coordenação Geral e do Interior constituíram Grupo de Trabalho especialmente para estudar o - problema de moradia para o funcionalismo federal em Brasília e oferecer sugestões conclusivas para resolvê-lo. 
SERVIDORES TRANSFERIDOS

O quadro a seguir revela o número de servidores transferidos de 1960 até junho de 1971

\begin{tabular}{|l|r|r|l|}
\hline \multicolumn{1}{|c|}{ Anos } & Servidores & Dependentes & Total \\
\hline 1960 & 2.474 & 5.394 & 7.868 \\
1961 & 1.314 & 4.263 & 5.577 \\
1962 & 823 & 2.242 & 3.065 \\
1963 & 575 & 1.657 & 2.232 \\
1964 & 268 & 898 & 1.166 \\
1965 & 352 & 880 & 1.232 \\
1966 & 320 & 1.005 & 1.325 \\
1967 & 422 & 1.525 & 1.947 \\
1968 & 714 & 2.636 & 3.350 \\
1969 & 889 & 2.794 & 3.683 \\
1970 & 2.018 & 5.767 & 7.785 \\
1971 (até junho) & 1.344 & 4.050 & 5.394 \\
\hline SOMA .......... & 11.513 & 33.111 & 44.624 \\
\hline
\end{tabular}

A intensificação do processo de transferência está demonstrada pelos números de 1968 para cá, especialmente 1970.

Em 1971, a média mensal tem sido de 224 funcionários e 675 dependentes, isto é, 899 pessoas, ou 10.788 até o fim do ano, pelo menos, superando 1960, ano da inauguração da Cidade, em que a média mensal foi de 654 pessoas, com 7.868 no final.

Observe-se que os números apresentados só se referem à Administração Dỉreta, não incluindo autarquias, emprêsas pủblicas e sociedades de economia mista, que vêm trazendo considerável e crescente contingente de servidores. 